\section{Infective Endocarditis caused by Gemella Sanguinis: A Case with Fever of Unknown Origin and Anemia}

Sir,

Infective endocarditis (IE), which is commonly associated with streptococcal or staphylococcal bacteriemia, has a wide range of clinical signs and symptoms. An emerging agent associated with IE is the genus Gemella. ${ }^{1}$ The genus Gemella is immotile, oxidase and catalase negative, facultatively anaerobic, and Gram-positive coccoid bacteria. They occur as commensals in the oral cavity, upper respiratory tract, and gastrointestinal tract, but are rare causes of disease in humans. In clinical practice, they are often seen as opportunistic pathogens. They may cause severe life-threatening infections, especially in immunocompromised patients with predisposing diseases. ${ }^{1}$ The identification of Gemella species with conventional methods is troublesome. In the past, they were classified in Neisseraceae family, but with consequent studies, they were identified as a different genus by $16 \mathrm{~S}$ rRNA genesequencing. ${ }^{1}$ Nowadays, the identification of Gemella spp can be done more easily with molecular and automated systems. There are six different species defined till recently: G. haemolysans, G. morbillorum, G. bergeri, G. sanguinis, G. palaticanis, and G. cuniculi. ${ }^{1} G$. haemolysans and G.morbillorum have been reported more frequent than $G$. sanguinis as causes of IE. ${ }^{2}$ To our knowledge, endocarditis associated with G. sanguinis was reported only twice in the literature. ${ }^{3,4}$ The first case was a 69 -year male patient with subacute endocarditis. ${ }^{3}$ There is no other detail available for the patient. The second case was a 69-year male with a subacute course of spiking fever, followed by central nervous system findings. ${ }^{4} \mathrm{He}$ had periodontal disease and an abscessed tooth; and was under prednisone treatment for severe chronic obstructive pulmonary disease. He was found to have only mitral valve involvement and was successfully treated with valve replacement. $A$ 56-year male presented with a two-month history of intermittent fever reaching up to $39^{\circ} \mathrm{C}$, shortness of breath, fatigue and anemia, which were detected in the tests performed before. His medical history was significant only for degenerative aortic and mitral valve disease, for which he has been on follow-up. He denied any recent invasive interventions preceding his complaints. Physical examination was noticeable for a fever of $38.8^{\circ} \mathrm{C}$, a pansystolic murmur $(3 / 6)$ in the mitral area radiating to the armpit, and a diastolic murmur (3/6) in the aortic area, and bilateral fine rales at the bases of lungs. Results of laboratory analyses were as follows: erythrocyte sedimentation rate $57 \mathrm{~mm} / 1 \mathrm{st} \mathrm{h}, \mathrm{C}$-reactive protein $60 \mathrm{mg} / \mathrm{L}$, leukocytes $9300 / \mu \mathrm{L}$, neutrophils $7050 / \mu \mathrm{L}$, lymphocytes $1350 / \mu \mathrm{L}$, hemoglobin 8.8 $\mathrm{g} / \mathrm{dL}$, mean corpuscular volume $88 \mathrm{fL}$, and platelets $136,000 / \mu \mathrm{L}$. Other biochemical analyses were within normal limits. Electro- cardiogram showed sinüs tachycardia, loss of $\mathrm{R}$ progression from lead V1 to V 3 and left ventricular hypertrophy. The chest $X$ ray was normal. Trans-esophageal echocardiography revealed advanced mitral and aortic regurgitations, two vegetations in the aortic valve measuring $1.4 \mathrm{~cm}$ and $1.8 \mathrm{~cm}$ in diameters, aortic perforation in the non-coronary cusp and suspicion of mitral valve perforation. Two of three separate blood culture bottles of BACTEC 9240 (Becton Dickinson, USA) gave positive signals. The samples of bottles were inoculated to blood and chocolate agar. Grown bacteria were oxidase and catalase-negative, Gram-positive cocci. Further identification was done by the Vitek 2 system (bioMérieux, France). The antibiotic susceptibility test was performed using a disc diffusion method according to Clinical and Laboratory Standards Institute (CLSI) recommendations (Streptococci species). The following antibiotics were tested for susceptibility: penicillin $(10 \mu \mathrm{g})$, ampicillin $(10 \mu \mathrm{g})$, vancomycin $(30 \mu \mathrm{g})$, and teicoplanin $(30 \mu \mathrm{g}){ }^{5}$ The bacterium was identified as $G$. Sanguinis, and it was susceptible to the antibiotics tested. After a 10-day course of intravenous penicillin $\mathrm{G}$ and gentamicin, his fever resolved and acute phase reactants returned to normal ranges. The size of the vegetations in the aortic valve decreased on the follow-up echocardiogram. The patient was transferred to the Cardiovascular Surgery Unitfor aortic, and possibly mitral valve replacement.

\section{CONFLICT OF INTEREST:}

The authors declared no conflict of interest.

\section{AUTHORS' CONTRIBUTION:}

$\mathrm{OE}$ : Involved in drafting the manuscript and revising it critically for important intellectual content and contributed to the analysis.

OE, EO: Contributed to the conception and design of the work and intellectual properties-related work; made contributions to the analysis.

\section{REFERENCES}

1. Collins MD. The genus Gemella. In: Dworkin M, Falkow S, Rosenberg E, Schleifer KH, Stackebrandt E, editors: The prokaryotes, third edition, New York: Springer press, New York, 2006: 511-18.

2. Chaudhry R, Mathur P, Dhawan B, Gaur S, Dey AB. Infections caused by Gemella spp: case reports from India. J Infect 2001; 43(2):152-5. doi: 10.1053/jinf.2001.0870.

3. Collins MD, Hutson RA, Falsen E, Sjöden B, Facklam RR. Description of Gemella sanguinis sp. nov., isolated from human clinical specimens. J Clin Microbiol 1998; 36(10):3090-3. doi: 10.1128/JCM.36.10.3090-3093.1998.

4. Shukla SK, Tak T, Haselby RC, McCauley CS Jr, Reed KD. Second case of infective endocarditis caused by Gemella sanguinis. WMJ 2002; 101(3):37-9.

5. Clinical and laboratory standards Institute (CLSI). Performance standards for antimicrobial susceptibility testing: Nineteen informational supplement. CLSI Document M100-S19, Clinical and laboratory standards Institute WVR, Suite 1400, Wayne, Pennsylvania, USA 
Omer Ekinci ${ }^{1}$ and Emrah Ozbek ${ }^{2}$

${ }^{1}$ Department of Hematology, Faculty of Medicine, Firat University, Elazig, Turkey

${ }^{2}$ Department of Cardiology, Faculty of Medicine, Yüzüncü Yıl University, Van, Turkey
Correspondence to: Dr. Omer Ekinci, Departme nt of Hematology, Faculty of Medicine, Firat University, Elazig, Turkey E-mail: dromere@hotmail.com

Received: June 08, 2020; Revised: October 18, 2020; Accepted: November 06, 2020

DOI: https://doi.org/10.29271/jcpsp.2021.09.1133

$\bullet \bullet \bullet \bullet \bullet \bullet \bullet \bullet \bullet$ 